Saudi Journal of Medicine

Abbreviated Key Title: Saudi J Med ISSN 2518-3389 (Print) |ISSN 2518-3397 (Online) Scholars Middle East Publishers, Dubai, United Arab Emirates Journal homepage: $\underline{\text { http://scholarsmepub.com/sjm/ }}$

Original Research Article

\title{
The Study of Non Operative Treatment for Acute Appendicitis (NOTA)
}

\author{
Abdul Ghani Qureshi ${ }^{1,3^{*}}$, Saadeldin Ahmed Idris ${ }^{2}$ \\ ${ }^{1}$ Assistant professor, Department of Surgery, Faculty of Medicine, Baqai Medical University, Karachi, Pakistan \\ ${ }^{2}$ Professor, Department of Surgery, Faculty of Medicine, University of Hail, KSA \\ ${ }^{3}$ Consultant of Surgery, Almikhwah General Hospital, Al-Baha, KSA
}

DOI: $10.36348 /$ sjm.2020.v05i01.003

| Received: 01.01.2020 | Accepted: 08.01.2020 | Published: 15.01.2020

*Corresponding author: Abdul Ghani Qureshi

\section{Abstract}

Management of patients in emergency departments is an important indicator of the quality of a healthcare system. In selected patients with acute appendicitis can we treat them by antibiotic therapy alone? The study aimed to assess the long-term efficacy of non-operative treatment in the management of uncomplicated acute appendicitis. A Prospective Cohort study was carried out in a periphery hospital, it included adult female patients satisfied the research criteria (January 2017 to December 2018). Those were including the clinical signs and symptoms of acute appendicitis, and radiological findings suggestive for acute appendicitis. Nonsurgically treated patients were divided in two groups based on the treatment outcome either successful or unsuccessful. It included 52 patients their mean age was $25.2 \pm 9.7$ years. The majority were from the age group $>20-30$ years $(46.2 \%)$. All had right iliac fossa pain, tenderness and rebound tenderness. Only in $43(82.7 \%)$ patients the ultrasound was diagnostic. All patients received combined antibiotics in the form of intravenous $3^{\text {rd }}$ generation Cephalosporin $1 \mathrm{gm}$ twice a day and Metronidazole $500 \mathrm{mg}$ three times a day. Successful cases were discharged on oral antibiotics for further 7 days. Successful, failure and recurrence rate were $93.8 \%, 7.69 \%$ and $6.3 \%$ respectively. Satisfaction questionnaire was filled by patients who treated conservatively and it revealed that $96.2 \%$ were satisfied from such type of management. In conclusion, the use of antibiotics for suspected acute non complicated appendicitis is effective and may avoid unnecessary appendectomy. Once nonsurgical management is started, close monitoring of patient's clinical condition is mandatory.

Keywords: Acute appendicitis, Conservative treatment, Successful rate, Failure rate, Recurrence rate, Satisfaction.

Copyright @ 2020: This is an open-access article distributed under the terms of the Creative Commons Attribution license which permits unrestricted use, distribution, and reproduction in any medium for non-commercial use (NonCommercial, or CC-BY-NC) provided the original author and source are credited.

\section{INTRODUCTION}

Acute appendicitis (AA) is the most common surgical emergency encountered compared with other non-traumatic acute abdomen [1]. Despite technologic advances, the diagnosis of appendicitis is still based primarily on the patient's history and the physical examination. Although most patients with AA can easily be diagnosed, for many of them the signs and symptoms are variable and a firm diagnosis can be difficult [2]. More routine use of imaging has improved diagnostic accuracy and identification of the majority of patients with uncomplicated appendicitis at admission [3]. Over a century, appendectomy has been the standard treatment for AA $[4,5]$. Some authors suggest that non operative management as effective alternative treatment [4]. Delaying surgery may increase the risk of finding perforated appendicitis and development of intra-abdominal abscesses and/or localized or diffuse peritonitis before surgery, with a higher rate of wound infections, medical complications, and increased longterm risk of adhesions and subsequent adhesive small bowel obstruction and infertility after surgery [6]. Despite growing experience of managing AA nonoperatively, still there is no consensus of most appropriate antimicrobial regimens [7]. Most treatment protocols include an initial course of intravenous antibiotics for 1-3 days, followed by oral antibiotics for 7 days. Usually, either a combination of a cephalosporin and tinidazole or broad-spectrum penicillin combined with a beta lactam inhibitor is being administered. In one trial, ertapenem has been used, leading to deserved criticism for inadequately using reserve antibiotics [4].

This study aimed to assess the long-term $(>12$ months) efficacy of non-operative treatment in the management of uncomplicated acute appendicitis (AA). As well to find out whether there is a specific antibacterial regimen associated with markedly higher percentage of successfully treated patients. 


\section{MATERIAL AND METHODS}

The study conducted at Almikhwah General Hospital, Baha, KSA after obtaining institutional ethical approval, the medical records of all female patients with uncomplicated acute appendicitis who have been managed via non operative methods during the period from January 2017 to January 2019 were examined. All patients were confirmed as a case of uncomplicated AA. The diagnosis was verified using ultrasound (US) in all cases. Non operative treatment in the form of an intravenous antibiotic regime composed of $3^{\text {rd }}$ generation cephalosporin $1 \mathrm{~g}$ BID and metronidazole $500 \mathrm{mg}$ TDS. Subsequent to antibiotic delivery, if symptoms did not improve within 48 hours, appendectomy was performed. Successful conservative treatment was defined as being discharged from the hospital following the resolution of appendicitis without the need for surgical intervention and no appendicitis during a follow up of 6 months. Recurrence in an earlier successfully conservatively managed patient was defined as a clinically diagnosed case of appendicitis due to the presence of repeated symptoms or disease, detected by imaging evaluation which required treatment. Repeated clinical evaluations and monitoring was done in follow-up clinic at 10 days, 30 days, 6 months and 1 year to assess recurrence. Patients whose clinical status improved were continued with oral antibiotics in form of Cefuroxime $500 \mathrm{mg}$ and metronidazole $500 \mathrm{mg}$ three times a day for a total of 7 days. In patients whose clinical condition did not improve, appendectomy was performed according to the usual practice by open technique. The appendix was sent for histological examination. Recurrence of appendicitis mandate surgical management.

The collected data were spread on master sheet, entered computer and managed statistically using SPSS. The numerical data was expressed as mean \pm SD. whereas, the categorical data were expressed as percentage and compared between groups using Student's t test. P value less than 0.05 was considered statistically significant.

\section{RESULTS}

Acute appendicitis was the diagnosis in 144 females. Patients with complicated appendicitis, recurrent appendicitis, and who did not accept the conservative treatment measures were excluded from the study. Remaining 52 female patients were satisfied the inclusion criteria so included for the final assessment. Their age ranged from 14 to 60 years, with a mean age of $25.2 \pm 9.7$ years. The majority of patients $(46.2 \%)$ were from the age group $>20-30$ years (Table $1)$.
Table-1: Distribution of appendicitis among age group

\begin{tabular}{|l|l|l|}
\hline Age group / year & Frequency & Percent \\
\hline$<20$ & 11 & 21.2 \\
\hline$>20-30$ & 24 & 46.2 \\
\hline$>30-40$ & 13 & 25.0 \\
\hline$>40-50$ & 2 & 3.8 \\
\hline$>50-60$ & 2 & 3.8 \\
\hline Total & $\mathbf{5 2}$ & $\mathbf{1 0 0 . 0}$ \\
\hline
\end{tabular}

The mean duration of symptoms was $1.65 \pm 0.73$ days (range, 1 to 5 days). The most presenting symptoms and signs as RIF pain, tenderness in the RIF and rebound tenderness were encountered in all patients. Less encountered symptoms were anorexia and nausea as seen in $48.1 \%$ and $36.5 \%$ respectively (Table 2). The mean WBC was $7.98 \pm 0.95$ (range, 3.4 to 27.3 cells). This study found that only $22.9 \%$ has raised WBCs > $10.000 \mathrm{cc}$ (Figure 1). All patients were diagnosed with the help of abdominal ultrasound scan (Figure 2). Only in $43(82.7 \%)$ patients the ultrasound was diagnostic. In the remaining $17.3 \%$ the diagnosis was depends on history and clinical examination.

Table-2: Presentation of the patients

\begin{tabular}{|l|l|l|}
\hline Sign \& symptoms & Frequency & Percentage \\
\hline RIF pain & 52 & 100 \\
\hline Rebound tenderness & 52 & 100 \\
\hline Anorexia & 25 & 48.1 \\
\hline Nausea & 19 & 36.5 \\
\hline Vomiting & 13 & 25.0 \\
\hline
\end{tabular}

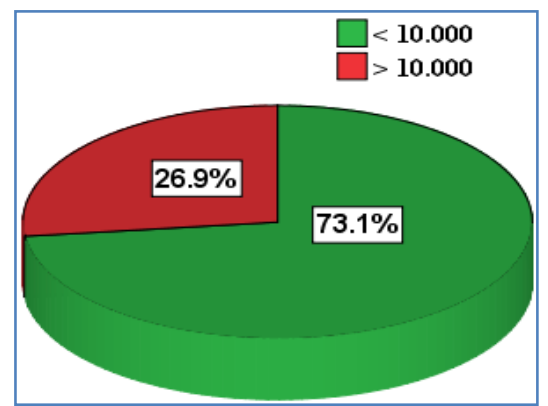

Fig-1: White blood cell count (WBCs) among patients

All patients received combined antibiotics in the form of intravenous $3^{\text {rd }}$ generation cephalosporin 1 gm twice a day and metronidazole $500 \mathrm{mg}$ three times a day.

Successful rate of conservative treatment regimen in this study was $93.8 \%$. Up on discharge, patients were given oral cefuroxime $500 \mathrm{mg}$ and metronidazole $500 \mathrm{mg}$ three times a day for 7 days. 
During repeated evaluation $4(7.69 \%)$ patients did not respond to our regimen of treatment, so treated by open appendectomy and specimens sent for histopathology that confirmed appendicitis. Failure of conservative treatment was not affected by initial WCBs count, duration of symptoms, presence of nausea, vomiting and anorexia during admission as $\mathrm{p}$ value was $0.7,0.4,0.2,0.3$ and 0.1 respectively.

In the group of patients treated conservatively the mean hospital stay was $1.9 \pm 0.96$ days and the mean analgesics need was $1.9 \pm 0.95$ days.

During one year follow up 3 out of $52(5.77 \%)$ patients presented with sign and symptoms of acute appendicitis were treated by appendicectomy, and the histopathology report came with acute appendicitis.

Satisfaction questionnaire was filled by the group of patients who treated conservatively revealed that $96.2 \%$ were satisfied from such type of management.

\section{DISCUSSION}

Appendicectomy is currently the mainstay treatment of acute appendicitis in our health care reflected by our study numbers (52 conservatively treated patients versus 92 surgically treated female patients), whereas conservative treatment was only occasionally adopted. The concept of conservative management of acute appendicitis over appendicectomy has been proposed for over two decades. There have been several randomized controlled trials and multiple systematic reviews looking at safety and efficacy of antibiotics alone versus appendicectomy in treating acute uncomplicated appendicitis [8].

The present study was designed to evaluate the effectiveness of conservative treatment in the management of uncomplicated acute appendicitis. The mean age in the present study was $25.2 \pm 9.7$ years (range, 14 to 60) which is in consistent with that reported in literature [1, 2, 9-12].

In the present study, majority of patients $46.2 \%$ belonged to the age group $>20-30$ years. This is in accordance with that reported in literature which suggests that acute appendicitis has higher incidence in 3rd decade of life [9-12].

The diagnosis of acute appendicitis is primarily a clinical one based on a consistent history and clinical presentation. However, radiology has become increasingly used to support the diagnosis. Ultrasonography is considered the first-line radiological investigation for the assessment of complicated appendicitis in which there is a question of an appendix mass or abscess. It is quick, cheap, and non-invasive and does not expose the patient to a radiation load [13].
In the current study we recommend a diagnostic algorithm using ultrasound as the primary imaging strategy after history taking, clinical examination and blood tests.

The majority of patients $82.7 \%$ had positive findings on ultrasonography of abdomen and pelvis suggestive of uncomplicated appendicitis. The sensitivity and specificity of ultrasonography for acute appendicitis in the literature are mentioned in table 3 [14-17].

Table-3: Sensitivity and specificity of ultrasonography in literature

\begin{tabular}{|l|l|l|}
\hline Authors & Sensitivity \% & Specificity \% \\
\hline $\begin{array}{l}\text { Van Randen } \text { et al. } \\
{[14]}\end{array}$ & 76 & 95 \\
\hline Pickuth et al. [15] & 87 & 74 \\
\hline Dsouza et al. $[16]$ & 92.2 & 88.9 \\
\hline Douglas et al. [17] & 94.7 & 88.9 \\
\hline
\end{tabular}

In the present study, pain and tenderness were the most common symptoms present in all patients followed by nausea/vomiting in $61.5 \%$ and anorexia in $48.1 \%$. These findings are in accordance with the literature [18-20].

As experience with non-operative treatment will increase, the length of antibiotic therapy will likely shorten, with the now rigid schedule adapting to a more patient-oriented course with cessation of therapy 1-2 days after significant clinical improvement, as in other abdominal infections [4].

Studies showed a variable period of intravenous antibiotics ranging from 1 to 3 days and 7 to 10 days of oral antibiotics were used thereafter. Variable combinations of penicillins, cephalosporins, carbopenems, or fluoroquinolones were used in combinations with a nitroimidazole [3].

Eriksson 1995 in the study of 20 patients treated conservatively used Cefotaxime 2 g 12 hourly and Tinidazole $0.8 \mathrm{~g}$ daily, then after discharged on Ofloxacin and Tinidazole for 10 days [21]. Winn et al. 2004 in the study of 48 patients treated conservatively used Gentamicin $6 \mathrm{mg} / \mathrm{kg}$ OD and metronidazole 1500 mg OD, then after discharged on Augmentin for 7 days [22]. Styrud et al. 2006 in the study of 128 patients treated conservatively used Cefotaxime 2 g 12 hourly and Tinidazole $0.8 \mathrm{~g}$ daily, then after discharged on Ofloxacin and Tinidazole for 10 days [23]. Hansson et al. 2009 in the study of 106 patients treated conservatively used Cefotaxime 1 g 12 hourly and metronidazole $500 \mathrm{mg}$ BD daily, then after discharged on Ciprofloxacin and metronidazole for 10 days [24]. Malik and Bari 2009 in the study of 40 patients treated conservatively used Ciprofloxacin $500 \mathrm{mg} 12$ hourly and metronidazole $500 \mathrm{mg} 8$ hourly, then after discharged on Ciprofloxacin and Tinidazole for 7 days 
[25]. Salminen et al. 2015 in the study of 257 patients treated conservatively used intravenous ertapenem sodium $(1 \mathrm{~g} / \mathrm{d})$ for 3 days, this was followed by 7 days of oral Levofloxacin $500 \mathrm{mg}$ once daily and Metronidazole $500 \mathrm{mg} 3$ times per day [5]. Whereas, in the current study intravenous $1 \mathrm{~g} 3^{\text {rd }}$ generation Cephalosporin twice a day in combination with $500 \mathrm{mg}$ Metronidazole three times a day at the time of diagnosis, there after continued with oral Cefuroxime $500 \mathrm{mg}$ and Metronidazole $500 \mathrm{mg}$ at the time of discharge for 7 days.

Criteria for converting to appendectomy were varied, but essentially constituted deterioration or failure to improve within 24 to 48 hours. A similar criterion was documented in literature [3].

In the current study $93.8 \%$ of patients treated with antibiotics were able to avoid surgery during the initial admission. The other $7.67 \%$ that fail to respond to antibiotics require appendectomy. A recurrence rate of non-operated patients within 1 year was $6.3 \%$. This finding was in accordance with that reported in the literature (Table 4) [5, 20-26].

The mean hospital stay was $1.9 \pm 0.96$ days. This was in consistent with the literature as the reported hospital stay ranged between 1 to 2 days [20-25].

Table-4: Successful rate and recurrence rate of conservative treatment of acute appendicitis in literature

\begin{tabular}{|l|l|l|l|}
\hline Study & Year & $\begin{array}{l}\text { Successful } \\
\text { rate }\end{array}$ & $\begin{array}{l}\text { Recurrence } \\
\text { rate }\end{array}$ \\
\hline $\begin{array}{l}\text { Eriksson \& Granstrom } \\
{[21]}\end{array}$ & 1995 & 95 & 37 \\
\hline Winn et al. $[22]$ & 2004 & 92 & 5 \\
\hline Styrud et al. $[23]$ & 2006 & 88 & 15 \\
\hline Hansson et al. $[24]$ & 2009 & 91 & 14 \\
\hline Malik \& Bari $[25]$ & 2009 & 95 & 10 \\
\hline Park et al. [26] & 2014 & 92.4 & 12.7 \\
\hline Salminen et al. $[5]$ & 2015 & 94.2 & 21.4 \\
\hline Gedam et al. $[20]$ & 2017 & 85.92 & 13.11 \\
\hline Current study & $\mathbf{2 0 1 9}$ & $\mathbf{9 3 . 8}$ & $\mathbf{6 . 3}$ \\
\hline
\end{tabular}

\section{CONCLUSION}

The results of the current study demonstrate that if patients are correctly addressed to the proper treatment option, starting from correct clinical evaluation, conservative treatment seems feasible alternative to appendectomy in management of uncomplicated acute appendicitis with acceptable low treatment failure and recurrence rate. First attack of uncomplicated acute appendicitis can be treated successfully by conservative treatment thereby avoiding appendectomy and its associated morbidity and mortality. However, conservative treatment requires monitoring and repeated re-evaluation of clinical condition of the patients to identify failure in improvement of clinical status, which mandate prompt surgical treatment. In conservative treatment we recommend the use of intravenous $1 \mathrm{~g} 3^{\text {rd }}$ generation Cephalosporin twice a day in combination with $500 \mathrm{mg}$ Metronidazole three times a day at the time of diagnosis, thereafter in respondents it will continued with oral Cefuroxime $500 \mathrm{mg}$ and Metronidazole 500 $\mathrm{mg}$ at the time of discharge for 7 days. Treatment failure on primary admission as well as the short- term recurrence after conservative treatment is low and acceptable. Reducing operative rate of such a common condition may also have an additional impact on human and surgical operating room resource utilization and have a further positive impact on social and health care costs. Further research needs to incorporate long-term follow-up before definitive best practice guidelines can be determined. The question still remains that by managing patients conservatively can we treat them by antibiotic therapy alone?.

\section{REFERENCES}

1. Idris, S. A., Hamza, A. A., Salih, A. O., Ali, M. E. A., Hafiz, M. M., \& Elsiddig, K. E. (2014). Timing and duration of antibiotic usage in appendectomies and its relation with surgical site infection. Open Science Journal of Clinical Medicine, 2(1), 19-23.

2. Idris, S. A., Shalayel, M. H., Awad, Y. O., Idris, T. A., Ali, A. Q., \& Mohammed, S. A. (2009). The sensitivity and specificity of the conventional symptoms and signs in making a diagnosis of acute appendicitis.Sudan Journal of Medical Sciences, 4(1).

3. Findlay, J. M., el Kafsi, J., Hammer, C., Gilmour, J., Gillies, R. S., \& Maynard, N. D. (2016). Nonoperative management of appendicitis in adults: a systematic review and meta-analysis of randomized controlled trials. Journal of the American College of Surgeons, 223(6), 814-824.

4. Becker, P., Fichtner-Feigl, S., \& Schilling, D. (2018). Clinical Management of Appendicitis. Visceral medicine, 34(6), 453-458.

5. Salminen, P., Paajanen, H., Rautio, T., Nordström, P., Aarnio, M., Rantanen, T., ... \& Sand, J. (2015). Antibiotic therapy vs appendectomy for treatment of uncomplicated acute appendicitis: the APPAC randomized clinical trial. Jama,313(23), 23402348.

6. Di Saverio, S., Sibilio, A., Giorgini, E., Biscardi, A., Villani, S., Coccolini, F., ... \& Catena, F. (2014). The NOTA Study (Non Operative Treatment for Acute Appendicitis): prospective study on the efficacy and safety of antibiotics (amoxicillin and clavulanic acid) for treating patients with right lower quadrant abdominal pain and long-term follow-up of conservatively treated suspected appendicitis. Annals of surgery, 260(1), 109-117.

7. Silina, E., Jurgele, A., Viksne, A., Abola, Z., Engelis, A., \& Petersons, A. (2016). Nonsurgical Management of Acute Uncomplicated Appendicitis in Children: the Analysis of Treatment Outcome in Relationship with Antimicrobial Regimens and 
Adverse Prognostic Factors. Acta Chirurgica Latviensis, 16(2), 12-16.

8. Allan, Z., Al-Habbal, Y. (2018). Non-Operative Management of Acute Appendicitis - Evidence versus Practice in Eastern Health, Victoria, Australia. J Surg Oper Care, 3(2): 205.

9. Jade, R., Muddebihalm, U., Naveen, N. (2016). Modified alvarado score and its application in the diagnosis of acute appendicitis. Int J Contemporary Medical Research, 3(5):1398-400.

10. Ramachandra, J., Sudhir, M., Sathyanarayana, B. (2013). Evaluation of modified alvarado score in preoperative diagnosis of acute appendicitis. IJ evolution of medical and dental sciences, 2(46):9019-29.

11. Lohar, H. P., Calcuttawala, M. A. A., Nirhale, D. S., Athavale, V. S., Malhotra, M., \& Priyadarshi, N. (2014). Epidemiological aspects of appendicitis in a rural setup. Medical Journal of Dr. DY Patil University, 7(6), 753.

12. Vaishnav, U., \& Chauhan, H. (2016). Evaluation of conservative management of acute Appendicitis in tertiary care hospital. IAIM, 3(2), 41-4.

13. Davies, S., Peckham-Cooper, A., \& Sverrisdottir, A. (2012). Case-based review: conservative management of appendicitis-are we delaying the inevitable?. The Annals of the Royal College of Surgeons of England, 94(4), 232-234.

14. Findlay, J. M., el Kafsi, J., Hammer, C., Gilmour, J., Gillies, R. S., \& Maynard, N. D. (2016). Nonoperative management of appendicitis in adults: a systematic review and meta-analysis of randomized controlled trials. Journal of the American College of Surgeons, 223(6), 814-824.

15. Pickuth, D., Heywang-Köbrunner, S. H., \& Spielmann, R. P. (2000). Suspected acute appendicitis: is ultrasonography or computed tomography the preferred imaging technique?. The European journal of surgery, 166(4), 315-319.

16. Dsouza, C., Martis, J., \& Vaidyanathan, V. (2013). Diagnostic efficacy of modified alvarado score over graded compression ultrasonography. Nitte University J Health Science, 3(3).

17. Douglas, C. D., Macpherson, N. E., Davidson, P. M., \& Gani, J. S. (2000). Randomised controlled trial of ultrasonography in diagnosis of acute appendicitis, incorporating the Alvarado score. Bmj, 321(7266), 919.

18. Bangla, G., \& Rao, P. S. (2013). Role of Alvarado score in the diagnosis of acute appendicitis. International Journal of Research in Medical Sciences, 1(4), 404.

19. Ekka, N. M. P., Singh, P. R., \& Kumar, V. (2016). A clinicopathological study of acute appendicitis in eastern India. International Journal of Medical and Dental Sciences, 5(2), 1145-1149.

20. Gedam, B. S., Gujela, A., Bansod, P. Y., \& Akhtar, M. (2017). Study of conservative treatment in uncomplicated acute appendicitis. International Surgery Journal, 4(4), 1409-1416.

21. Eriksson, S., \& Granström, L. (1995). Randomized controlled trial of appendicectomy versus antibiotic therapy for acute appendicitis. British journal of surgery, 82(2), 166-169.

22. Winn, R. D., Laura, S., Douglas, C., Davidson, P., \& Gani, J. S. (2004). Protocol- based approach to suspected appendicitis, incorporating the Alvarado score and outpatient antibiotics. ANZ journal of surgery, 74(5), 324-329.

23. Styrud, J., Eriksson, S., Nilsson, I., Ahlberg, G., Haapaniemi, S., Neovius, G., ... \& Granström, L. (2006). Appendectomy versus antibiotic treatment in acute appendicitis. a prospective multicenter randomized controlled trial. World journal of surgery, 30(6), 1033.

24. Hansson, J., Körner, U., Khorram- Manesh, A., Solberg, A., \& Lundholm, K. (2009). Randomized clinical trial of antibiotic therapy versus appendicectomy as primary treatment of acute appendicitis in unselected patients. British Journal of Surgery: Incorporating European Journal of Surgery and Swiss Surgery, 96(5), 473-481.

25. Wiegering, V. A., Kellenberger, C. J., Bodmer, N., Bergstraesser, E., Niggli, F., Grotzer, M., \& Bourquin, J. P. (2008). Conservative management of acute appendicitis in children with hematologic malignancies during chemotherapy-induced neutropenia. Journal of pediatric hematology/oncology, 30(6), 464-467.

26. Park, H. C., Kim, M. J., \& Lee, B. H. (2014). The outcome of antibiotic therapy for uncomplicated appendicitis with diameters $\leq 10 \mathrm{~mm}$. International Journal of Surgery, 12(9), 897-900. 